\title{
СОВРЕМЕННЫЕ ТЕНДЕНЦИИ В ДЕЯТЕЛЬНОСТИ КОНСУЛЬСКИХ СЛУЖБ В УСЛОВИЯХ ГЛОБАЛИЗАЦИИ
}

\begin{abstract}
Аннотация: Данная статья посвящена современным тенденциям трансформации консульских функций в условиях глобализации. Радикальные изменения в современных мирохозяйственных связях и мировых миграционных процессах приводят к пониманию важности и значимости правового регулирования консульских отночений с точки зрения, как международного, так и национального права. В исследовании, консульское право и консульская служба рассматриваются через призму новых вызовов, связанных с такими явлениями, как рост взаимных поездок граждан, природные бедствия, гражданские войнь, множественное гражданство, международное трудоустройство, пенсионные вопросы, похищение детей, принудительные браки, секс-туризм и торговля людьми, которые оказывают действенное влияние на трансформацию консульских функиий на современном этапе. Указанные факторы обусловливают рост спроса на качественные и эффективные консульские услуги, что, в свою очередь, влияет на трансформацию консульских функций в современных условиях. логико-правовой, анализа, системно-структурный, диалектический, социально-правовой, сравнительно-правовой, историко-правовой, синергетический, конкретно-правовой, сравнительный Исследование позволило выделить три основных направления деятельности правительств в данной сфере: расширение консульских функиий в соответствии со спросом, управление ожиданиями с целью влияния на возрастающий спрос, введение новществ в сферу консульских услуг для удовлетворения спроса. Проанализирован опыт стран дальнего зарубежья по внедрению новшеств в сферу консульской деятельности, который позволил выделить три категории новшеств: коммуникационные, технологические новиества и партнерство. В статье дается характеристика особенностям современных межгосударственных соглашений по консульским вопросам, отражающим спрос на растущзий объем консульской деятельности в условиях глобализации.
\end{abstract}

Ключевые слова: Глобализация, соипсіl service, консульские услуги, коммуникационные новшества, технологические новшества, применение ИКТ, сотрудничество, межгосударственное сотрудничество, сотрудничество с ННО, консульские функиии.

Abstract: This article is dedicated to the modern trends of the transformation of consular functions in the conditions of globalization. Radical changes in modern global economic connections and migration processes demonstrate the importance and significance of the legal regulation of consular relations from the perspectives of both international and national laws. In this research, the consular law and consular service is being examined through the prism of new challenges associated with such phenomena as increased travel, natural disasters, civil wars, multiple citizenship, international employment, pension issues, child abductions, forced marriages, sex tourism and human trafficking, all of which significantly impact the transformation of consular functions at the present stage. These factors substantiate the growth in demand for quality and efficient consular services, which in turn affect the transformation of consular functions in the modern conditions. This research allowed the author to highlight three key vectors of the work of governments in this area: expansion of consular functions in accordance with demand; management of expectations for the purpose of affecting the growing demand; introduction of improvements into the sphere of consular services in order to meet the demands.

Keywords: Consular services, Communication innovations, Technological innovation, ICT, Collaboration, International cooperation, NGO partnership, Consular functions, Consulate, Globalization.

\section{Предисловие}

а протяжении последних лет мировое сообщество является свидетелем очевидного развития международных связей, которые год от года приобретают все более динамичный характер. Актуальность данной темы обусловлена, прежде всего, тем, что процессы глобализации, имеющие место в настоящее время, приводят к расширению отношений между государствами, юридическими лицами и гражданами различных стран в самых разнообразных сферах общественной жизни, науки, экономики, торговли, культуры и туризма. 
DOI: $10.7256 / 1811-9018.2016 .10 .15711$

При цитировании этой статьи сноска на dоі обязательна

Международное право в XXI веке

Новые проблемы, которые возникли в мировом сообществе в конце XX и начале XXI вв., особенно угроза международного терроризма, религиозного экстремизма и фундаментализма, торговля людьми требуют дальнейшего совершенствования деятельности консульских учреждений и ее правовых основ, а также принятия радикальных мер защиты интересов своих граждан и государства.

Анализ статистической информации в различных странах мира показывает постоянно растущий объем консульской деятельности государств и увеличение количества консульских учреждений, что в свою очередь подтверждает влияние этого феномена на развитие консульского права и необходимость его детального и всестороннего исследования.

Создание безвизовых зон, активизация процессов миграции и многое другое в условиях стремительно меняющегося мира вынуждают государства вести более активный поиск адекватных решений. Разумеется, это в полной мере относится и к дальнейшему выстраиванию архитектуры консульской службы и ее качественной модернизации на перспективу.

В этой связи многие исследователи и ученые во всем мире уделяют большое внимание изучению современных вызовов, которые приводят к пересмотру государствами роли консулов и консульских институтов в целях эффективной защиты интересов и прав своих граждан. В современном мире, консульское право, и консульская служба тщательно изучаются через призму новых вызовов, связанных с такими явлениями, как рост взаимных поездок граждан, природные бедствия, гражданские войны, множественное гражданство, международное трудоустройство, пенсионные вопросы, похищение детей, принудительные браки, секс-туризм и торговля людьми.

Правительства большинства стран своевременно реагируют на вызовы, стоящие перед консульскими службами, в связи с чем, ими принимаются соответствующие меры.

\section{1. Трансформация консульских функций: спрос и предложение}

На сегодняшний день консульские службы работают в постоянно меняющейся обстановке. Эта тема сейчас активно обсуждается в научной литературе и в СМИ многих стран. Как отмечает один из ведущих специалистов в области консульского права и консульской службы «Развитие и изменение международных отношений диктуют необходимость совершенствования консульских отношений между странами, внесения соответствующих коррективов в практику консульской службы [1, с.193]. Здесь мы более детально рассмотрим, какие факторы влияют на рост, спроса на консульскую службу, а также соответствующие этому характер и особенности предложения, другими словами, каким образом консульская служба должна реагировать на возрастающий спрос.

В последние годы растет спрос на качественные и эффективные консульские услуги. Это связано с несколькими факторами, среди которых рост числа взаимных поездок граждан и рост числа трудовых мигрантов. Например, более 2.8 миллионов граждан Канады живут в других странах на постоянной основе. Согласно данным журнала «The Economist», количество граждан Китая и Индии, проживающих в других государствах, составляет 50 и 22 миллиона человек соответственно. Одновременно наблюдается рост количества туристических поездок. Например, в 2011 году количество граждан Австралии, посетивших зарубежные страны в качестве туристов, составило 7,6 миллионов человек.

Второй фактор - это экономическая выгода, которую развивающиеся государства получают от денежных переводов трудовых мигрантов. Такие денежные переводы имеют существенный характер для экономики многих стран, и в этой связи защита прав и интересов трудовых мигрантов является важным направлением внешней политики многих развивающихся государств.

Третий фактор - это трансформация понятия «граждане в бедственном положении». По сравнению с предыдущими годами в настоящее время люди часто путешествуют в страны с нестабильной внутриполитической обстановкой, а также растет количество экстремальных туристов.

Помимо этого, значительно усложняют консульскую практику государств и такие факторы, как множественное гражданство, новые виды туризма (например, медицинский туризм), похищение детей и транснациональный терроризм. Соответственно, вышеназванные факторы существенно меняют природу спроса на консульские услуги, которые должны адекватно отражать возникшие нужды и ожидания граждан. Как отмечает Карин Тиндал, «консульские учреждения получают положительный отзыв в тех случаях, когда они проявляют способность спасать своих граждан. Когда они не справляются с очевидной, но не однозначной задачей «оказания помощи гражданам за границей» их критикуют» [2, с. 106-107] 
DOI: $10.7256 / 1811-9018.2016 .10 .15711$

При цитировании этой статьи сноска на doi обязательна

Право и политика $10(202) \cdot 2016$

\section{2. Новшества как эффективный способ удовлетворения спроса на консульские услуги: коммуникация, технология и партнерство.}

Как уже было отмечено, многие страны эффективно справляются с современными вызовами путем внедрения новшеств в сферу консульской деятельности. Практика многих государств показывает, что внедренные новшества можно разделить на три категории: коммуникационные новшества, технологические новшества и партнерство.

Превентивная коммуникация имеет универсальный характер для многих консульских служб. Советы путешественникам являются основным аспектом консульских функций, однако невозможно достичь эффективной коммуникации, ограничиваясь только советами и информацией для путешественников о возможных рисках посещения той или иной страны. Веб-сайты консульских учреждений остаются основным универсальным инструментом для консульской коммуникации, но они отличаются качеством дизайна и эффективностью. Многие исследователи призывают государства запустить процесс формальной экспертизы (например, каждый новый документ, прежде чем он будет включён в библиотеку, должен пройти минимум три этапа формальной экспертизы: это контроль технической корректности (technical accuracy review), языка (читабельности) (language review) и метаданных (metadata review)) для обеспечения точности, своевременности и полноты публикуемой рекомендательной информации.

В результате широкого применения мобильных телефонов многие страны начали использовать SMSсообщения в качестве нового инструмента консульской коммуникации. Например, Великобритания запустила проект "welcomeSMSmessages" для стимулирования онлайн-регистрации своих граждан за рубежом (по прибытию в зарубежную страну гражданин Великобритании получает смс, где консульское учреждение приветствует данного гражданина и рекомендует зарегистрироваться на сайте консульского учреждения). Некоторые консульские учреждения очень активно пользуются возможностями социальных сетей. Госдепартамент США имеет более 600 аккаунтов (включая аккаунты для консульской коммуникации) в социальных сетях, и они активно используются не только в информационных целях, но и являются эффективной площадкой для общения с гражданами США [6].

На сегодняшний день одним из актуальных вопросов является применение ИКТ в осуществлении консульской деятельности. Практика многих стран свидетельствует о том, что внедрение ИКТ может позитивно отразиться на качестве оказываемых консульских услуг. Действительно внедрение Консульским управлением МИД Республики Узбекистан заполнение формы визовой анкеты через интернет намного ускорило и улучшило качество оказания консульской услуги http://evisa.mfa.uz/evisa_ru/.

Грамотное использование технологий может внести большой вклад и в превентивную коммуникацию. Удобный интерфейс, алгоритм, и дизайн веб-сайта могут способствовать повышению эффективности работы. Например, в период с 2004 по 2007 год сайт Госдепартамента США www.travel.state.gov, специализирующийся на консульских вопросах, тщательно изучался специалистами по ИТ. В результате проведенного исследования было выявлено, что сайт не отвечает требованиям. В качестве одной из основных причин указывалась некомпетентность ответственных сотрудников в вопросах ИКТ. В результате управление сайтом было передано компании, которая специализируется в ИКТ, в том числе в информационной безопасности, графическом дизайне, архитектурах сайта и веб-навигации [7].

Однако внедрение ИКТ в деятельность консульской службы вызывает определенные вопросы, которые активно обсуждаются в научных кругах. Какие меры нужно предпринять, чтобы внедрение ИКТ гарантировало защиту персональных данных, предотвращало случаи мошенничества и обеспечивало кибербезопасность? Какие услуги нужно оцифровать, а какие должны предоставляться людьми? Каждое государство, внедряя ИКТ, должно, в первую очередь, найти ответы на данные вопросы и обеспечить информационную безопасность.

Помимо возложения ответственности на индивидов путем управления ожиданиями правительства также предпринимают попытки для разделения ответственности. Для оказания более эффективных консульских услуг и разделения ответственности правительства многих стран осуществляют сотрудничество с другими странами, организациями, институтами и представителями гражданского общества. Проведенные в этой области исследования выявили три основных направления такого сотрудничества:

- сотрудничество в рамках надгосударственных институтов

- межгосударственное сотрудничество

- сотрудничество с частным сектором и ННО.

Первая категория охватывает сотрудничество европейских стран по консульским вопросам в рамках ЕС. В качестве примера можно привести институт европейского гражданства и право граж- 
DOI: $10.7256 / 1811-9018.2016 .10 .15711$

При цитировании этой статьи сноска на dоі обязательна

Международное право в XXI веке

дан ЕС на дипломатическую и консульскую защиту. Маастрихтский договор о создании Европейского союза содержит нововведения относительно создания и деятельности Европейского Союза. Важное место среди них занимает учреждение гражданства Европейского Союза, или, как его весьма часто называют, единого общеевропейского гражданства. Этому посвящены ст. 8-8е Договора о Европейском Союзе. Хотя вопросы гражданства регламентируются внутренним законодательством любого государства, вместе с тем отдельные составляющие данного правового института, как например, порядок приобретения и утраты гражданства, правовой статус апатридов и бипатридов и др. требуют не только внутригосударственного, но и международно-правового регулирования. Маастрихтский договор ясно и недвусмысленно говорит именно о гражданстве Европейского Союза, объединяющего ныне 28 суверенных государств Европы, в каждом из которых миллионы своих собственных граждан.

Статья 8 Договора о создании ЕС предоставляет гражданам Европейского Союза, находящимся за его пределами, право пользоваться в случае необходимости защитой дипломатических представительств и консульских миссий любой страны - участницы ЕС, причем на тех же условиях, что и граждане данного государства. Это весьма специфичный атрибут единого общеевропейского гражданства, который был впервые закреплен в Маастрихтском договоре. Достаточно обратить внимание лишь на то, что речь идет о дипломатической и консульской защите граждан Евросоюза, предоставляемой именно государством-участником, но никак не самим Евросоюзом. Маастрихтский договор фактически подразумевает солидарную ответственность стран-участниц за дипломатическую и консульскую защиту граждан Евросоюза.

Межгосударственное сотрудничество подразумевает обмен консульскими услугами и оказание содействия по определенным специфическим вопросам. Венская конвенция о консульских сношениях предусматривает оказание консульских услуг от имени третьего государства, и многие межгосударственные соглашения внедрили эту практику, разделив тем самым ответственность между договаривающимися государствами.

В последние годы для консульских служб становится значимым сотрудничество с частным сектором и гражданским обществом. Например, сотрудничество со страховыми компаниями распределило ответственность между государством и страховыми компаниями в вопросах оказания помощи гражданам в экстренных случаях. Такие страны, как Голландия, Австралия и
Великобритания активно пропагандируют услуги по страхованию путешествий. В Австралии в 2009 был принят соответствующий законодательный акт, предусматривающий обязательное страхование путешествий. А в Китае действует закон, обязывающий китайских бизнесменов страховать свой зарубежный бизнес [8]. Во многих странах сотрудничество с туристической индустрией становится неотъемлемой частью деятельности консульских служб, и практика этих государств свидетельствует о том, что такое сотрудничество приносит эффективные результаты в плане обеспечения безопасности туристов. Например, британская правительственная «Группа заинтересованных лиц по консульским вопросам», которая собирается два раза в год для планирования и координации политики по консульским вопросам, помимо государственных органов, состоит из туристических агентов, страховых компаний, авиакомпаний, публикующих туристические гиды издательств и ННО [9].

Также правительства активно сотрудничают с различными ННО по консульским вопросам. Так, в частности, Великобритания сотрудничает с более 400 ННО в вопросах обеспечения нормальных условий содержания для заключенных из числа граждан Великобритании.

\section{3. Особенности современных международных соглашений по консульским вопросам}

Последние годы в научных кругах широко обсуждается вопрос реформирования Венской конвенции о консульских сношениях, но, к сожалению, государства не проявляют должной инициативы для пересмотра данной конвенции или разработки нового многостороннего соглашения. Вместо этого государства предпочитают осуществлять сотрудничество по консульским вопросам на двустороннем или региональном уровне. Исследования, проведенные в этом направлении, показали, что в целях повышения эффективности оказываемых консульских услуг государства чаще всего сотрудничают в сферах совместного оказания консульских услуг, управления в критических ситуациях, защиты прав детей и семей, оказания содействия национальным диаспорам.

Возрастающий спрос на качественные консульские услуги стал импульсом для развития сотрудничества в области консульской помощи и защиты. Правовым основанием для совместного оказания консульских услуг является статья 8 Венской конвенции, которая дает право государствам осуществлять консульские функции в принимающем государстве от имени третьих стран (в случае согласия принимающе- 


\section{Право и политика $10(202) \cdot 2016$}

го государства). Такие соглашения заключаются чаще всего между странами, имеющими тесные отношения. Страны Содружества наций имеют богатый опыт в этой сфере, и все страны Содружества имеют соглашения с Великобританией, которые предусматривают оказание со стороны Великобритании консульской защиты гражданам стран-членов Содружества. Меморандум о взаимопонимании, подписанный в 2012 году между Великобританией и Канадой, выражает намерение договаривающихся сторон «совместно приобретать и использовать дипломатические и консульские помещения, оказывать консульские услуги, тесно сотрудничать в чрезвычайных ситуациях для оптимизации деятельности дипломатических служб обоих государств» [10].

Как уже отмечалось выше, в настоящее время растет количество экстремальных туров, и многие любители острых ощущений посещают страны с нестабильной внутриполитической обстановкой. В этой связи и с учетом невозможности краткосрочного и долгосрочного прогноза природных катаклизмов, государства уделяют большое внимание вопросам сотрудничества в сфере управления в чрезвычайных ситуациях. Происходящие в мире события вынуждают государства предпринимать более активные меры по консульской защите своих граждан в чрезвычайных ситуациях. Также растет общественное давление на консульские учреждения в случае неэффективного управления кризисными ситуациями. Например, эвакуация граждан Канады во время войны в Ливане в 2006 году имела противоположныци характер, так как правительство Канады не стало эвакуировать канадских граждан с двойным гражданством. А меры, предпринятые правительством Швеции по защите своих граждан, пострадавших в результате цунами в Таиланде, были организованы неэффективно и на очень низком уровне, за что и были подвергнуты критике [11]. В результате эти страны пересмотрели свою концепцию по оказанию консульской защиты в чрезвычайных ситуациях, что привело к существенному реформированию ими консульской службы.

Средства коммуникации становятся важным элементом в управлении кризисными ситуациями и расширяют платформу для сотрудничества в этой сфере. Например, онлайн-платформа Госдепартамента США «eDiplomcy» рассматривается как одна из самых важных и перспективных сфер развития в рамках Глобальной партнерской инициативы Госдепартамента. В настоящее время есть несколько позитивных примеров действенной инициативы в этой области: функционирование посольства США в Мехико, посольства Мексики в Вашингтоне, Отдела по делам Мексики в главном управлении Госдепартамента (Mexican Affairs office in State Headquarters), а также Министерства иностранных дел Мексики. Все эти институты ведут тесное сотрудничество по широкому спектру проблем: например, они координируют усилия по предотвращению стихийных бедствий и ликвидации их последствий в приграничных регионах с использованием глобальной сети и облачных инструментов.

В рамках официального сотрудничества государств в этом направлении растет количество региональных инициатив и соглашений. В рамках ACЕАН функционирует Совет по миграционным и консульским вопросам, который регулярно собирает официальных лиц из стран АСЕАН. В 2012 году данным Советом была утверждена инициатива по принятию совместных мер и оказанию консульской защиты всем гражданам стран АСЕАН во время чрезвычайных ситуаций в-третьих странах. Рабочая программа АCEAН по управлению кризисными ситуациями является первым в мире документом, в котором юридически закреплены положения «Рамки действий Хего» (В январе 2005 года в японской префектуре Хего под эгидой ООН состоялась международная конференция по устранению последствий стихийных бедствий, на которой были приняты Рамки действий, определившие стратегические цели и приоритетные направления деятельности в работе по ликвидации последствий стихийных бедствий во всем мире в период с 2005 по 2015 гг.) [12].

Страны, которые имеют большое количество трудовых мигрантов в зарубежных странах, предпринимают активные шаги по защите прав и интересов этих граждан. Так, Индия ведет активную внешнеполитическую деятельность по налаживанию сотрудничества в данном направлении и является рекордсменом по количеству межгосударственных соглашений, направленных на социальную защиту трудовых мигрантов из Индии (например, Индия подписала такие соглашения со странами Персидского залива, Иорданией и Малайзией) [13]. Филиппины (количество трудовых мигрантов составляет 8,5 миллионов человек) заключили соглашения по защите трудовых прав своих граждан с такими странами, как Южная Корея, Бахрейн, Япония и Канада.

\section{Заключение}

Исследование новых тенденций в деятельности консульских служб на современном этапе позволяют сформулировать следующие выводы. 
DOI: $10.7256 / 1811-9018.2016 .10 .15711$

При цитировании этой статьи сноска на doi обязательна

Международное право в XXI веке

Новые проблемы, которые возникли в мировом сообществе в конце XX и начале XXI вв., особенно угроза международного терроризма, религиозного экстремизма и фундаментализма, торговля людьми требуют дальнейшего совершенствования деятельности консульских учреждений и его правовых основ, а также принятия радикальных мер защиты интересов своих граждан и государства.

Сегодня многие правительства своевременно реагируют на вызовы, стоящие перед консульскими службами и очень часто ими предпринимаются аналогичные меры: проводят широкую информационно-пропагандистскую деятельность; внедряют ИКТ для консультации, регистрации своих граждан, выдачи и обмена паспортов; наращивают сотрудничество с частным сектором, ННО, другими странами и международными организациями. Эти шаги, предпринимаемые государствами для повышения эффективности оказываемой консульской помощи являются только первыми шагами в удовлетворении существующего спроса.

Также необходимо отметить, что заключаемые на современном этапе межправительственные соглашения в сфере консульских вопросов приобретают практический характер и нацелены на решение конкретных задач (например, обеспечение социальной защиты для зарубежных рабочих). Предметом многих межправительственных соглашений являются сотрудничество в области защиты граждан в чрезвычайных ситуациях, медицинской защиты туристов, противодействия похищению детей, защиты трудовых прав зарубежных рабочих и т.п.

Мы полагаем, что пришло время пересмотра Венской конвенции о консульских сношениях или разработки нового многостороннего соглашения, так как данная конвенция уже не отвечает реалиям сегодняшнего дня. Поэтому государства предпо- читают заключать двусторонние или региональные соглашения по консульским вопросам.

Весьма интересен опыт стран-участниц Евросоюза по дипломатической и консульской защите граждан ЕC. В Маастрихтском договоре впервые был закреплен специфичный атрибут единого общеевропейского гражданства, который фактически, подразумевает солидарную ответственность государств-участников Евросоюза.

В целях оптимизации консульских сношений в рамках СНГ предлагается разработать и принять Консульскую конвенцию СНГ, в которой можно было бы предусмотреть солидарную ответственность стран-участниц СНГ, так как у большинства стран СНГ, кроме России, не во всех странах имеются дипломатические представительства.

В рамках официального сотрудничества государств в этом направлении растет количество региональных инициатив и соглашений. В рамках ACЕАН функционирует Совет по миграционным и консульским вопросам, который регулярно собирает официальных лиц из стран АСЕАН. В 2012 году данным Советом была утверждена инициатива по принятию совместных мер и оказанию консульской защиты всем гражданам стран АСЕАН во время чрезвычайных ситуаций в-третьих странах.

Таким образом, вышеприведенный материал и практика государств еще раз свидетельствуют о том, что консульские функции претерпели значительные изменения ввиду возрастающего спроса на консульские услуги. Примечательным является тот факт, что вопросы эффективной консульской защиты являются приоритетным направлением внешней политики не только развитых стран, но и развивающихся стран. Некоторые развивающиеся страны даже опережают развитые государства по эффективности введенных новшеств в консульскую службу своих стран.

\section{Библиография:}

1. Лапин Г.Е. Консульская служба: Учебное пособие. - 3 - изд., перераб. и доп. - М.: Международные отношения, 2012.

2. Karen Tindall, "Governments' Ability to Assist Nationals in Disasters Abroad: What Do We Know about Consular Emergency Management?" Journal of Contingencies and Crisis Management 20.2 (2012).

3. Xia Liping, "China's Consular Service Reformand Changesin Diplomacy," in Consular Affairs and Diplomacy (Leiden: Martinus Nijhoff, 2011)

4. International Organization for Migration and Migration Policy Institute, Developing a Road Map for Engaging Diasporas in Development: A Handbook for Policymakers and Practitioners in Home and Host Countries, 2012, online: http://www.gfmd. org/documents/pfp/diasporahandbook/Diaspora_Handbook_For\%20Web_17April2012.pdf

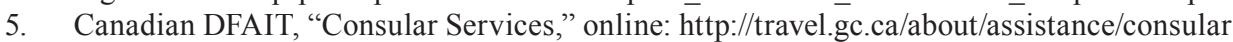

6. Fergus Hanson, Baked In and Wired: eDiplomacy@State, Brookings Institute, October 2012, online: http://www.brookings. edu/research/reports/2012/10/25-diplomacy-hanson

7. Donna Hamilton, "The United States Experience," in Consular Affairs and Diplomacy (Leiden: Martinus Nijhoff, 2011)

8. XiaLiping, "China's Consular Service Reformand Changesin Diplomacy," in Consular Affairs and Diplomacy (Leiden: Martinus Nijhoff, 2011)

9. Maaike Okano-Heijmans, "Changein Consular Assistance and the Emergence of Consular Diplomacy," chapter 1 in Consular Affairs and Diplomacy (Leiden: Martinus Nijhoff, 2011) 
DOI: $10.7256 / 1811-9018.2016 .10 .15711$

При цитировании этой статьи сноска на dоі обязательна

Право и политика $10(202) \cdot 2016$

10. DFAIT, "Further Strengthening the Canada-United Kingdom Partnership," 24 September 2012, online: http://www.international.gc.ca/media/aff/news-communiques/2012/09/24a.aspx?lang=eng\&view=d.

11. Stephanie Buus, "The People's Home goes Gulliver: Sweden and the 2004 tsunami crisis" 1(3-4) International Journal of Tourism Anthropology (2011); Sweden and the Tsunami: Evaluation and Proposals, Swedish Tsunami Commission, Stockholm, 2005.

12. ASEAN, Agreement on Disaster Management and Emergency Response, Work Programme for 2010-2015, online: http:// www.asean.org/resources/publications/asean-publications/item/asean-agreement-on-disaster-management-and-emergencyresponce-work-programme-for-2010-2015

13. Piyasiri Wickramasekara, "Something is Better than Nothing: Enhancing the protection of Indian migrant workers through Bilateral Agreements and Memoranda of Understanding," Migrant Forum in Asia, February 2012

\section{References (transliterated):}

1. Lapin G.E. Consulskaya slujba: Uchebnoye posobiye. - 3 - izd., pererab. i dop. - M.: Mejdunarodniye otnosheniya, 2012.

2. Karen Tindall, "Governments' Ability to Assist Nationals in Disasters Abroad: What Do We Know about Consular Emergency Management?" Journal of Contingencies and Crisis Management 20.2 (2012).

3. Xia Liping, "China's Consular Service Reformand Changesin Diplomacy," in Consular Affairs and Diplomacy (Leiden: Martinus Nijhoff, 2011)

4. Fergus Hanson, Baked In and Wired: eDiplomacy@State, Brookings Institute, October 2012, online: http://www.brookings. edu/research/reports/2012/10/25-diplomacy-hanson

5. Donna Hamilton, "The United States Experience," in Consular Affairs and Diplomacy (Leiden: Martinus Nijhoff, 2011)

6. Xia Liping, "China's Consular Service Reformand Changesin Diplomacy," in Consular Affairs and Diplomacy (Leiden: Martinus Nijhoff, 2011)

7. Maaike Okano-Heijmans, "Changein Consular Assistance and the Emergence of Consular Diplomacy," chapter 1 in Consular Affairs and Diplomacy (Leiden: Martinus Nijhoff, 2011)

8. Stephanie Buus, "The People's Home goes Gulliver: Sweden and the 2004 tsunami crisis" 1(3-4) International Journal of Tourism Anthropology (2011); Sweden and the Tsunami: Evaluation and Proposals, Swedish Tsunami Commission, Stockholm, 2005.

9. Piyasiri Wickramasekara, "Something is Better than Nothing: Enhancing the protection of Indian migrant workers through Bilateral Agreements and Memoranda of Understanding," Migrant Forum in Asia, February 2012 